\title{
Optimization of railway infrastructures rehabilitation based on multicriteria analysis
}

\author{
Paula Couto ${ }^{1, *}$, Filipa Salvado $^{2}$, and Maria João Falcão Silva ${ }^{1}$ \\ ${ }^{1}$ LNEC, Buildings Department, Av. Brasil, 101, 1700-066 Lisboa, Portugal
}

\begin{abstract}
The socio-economic objectives of transport projects are generally related to the improvement of travel conditions for goods and passengers as well as the improvement of the quality of the environment and the wellbeing of the served population.

Railways infrastructure projects are always complex because of the many variables involved. In railway rehabilitation, in particular, social, economic and environmental variables take on considerable importance. These variables contribute strongly to the selection of the intervention project to be performed. Historically, multicriteria evaluation methods were developed to select the best alternative from a set of competing options. Multicriteria Analysis is applied for comparison of alternative projects, allowing taking into account different criteria simultaneously. It presents a framework in which all the stakeholders can participate actively in the process of decision making and in the explicit resolution of problems. The paper intends to frame the multicriteria analysis with the purpose of its implementation in railway investment projects concerning rehabilitation interventions. In this sense, its importance and potential will be highlighted for several stakeholders in the decision-making process, as well as the objectives and criteria definition for a practical implementation.
\end{abstract}

\section{Introduction}

Multicriteria analysis emerged in the 1960s as a decision support tool, and it was immediately applied in the elaboration of comparative analyses of alternative projects or of heterogeneous (multicriteria) measures. The method is intended to help policy-makers integrate different options into their actions, reflecting on the views of different actors in a retrospective or prospective framework.

The involvement of policy-makers in the process is one of the central elements of the approach. The results are, in general, guiding decisions of an operational nature or for the presentation of recommendations for future activities [1]. Multicriteria analysis can be organized with a view to producing a simple synthetic conclusion at the end of the evaluation or, on the contrary, to produce conclusions tailored to the preferences and priorities of different stakeholders.

The multicriteria analysis is like the techniques adopted in the field of organizational development or management of information systems and resembles Cost Benefit Analysis,

\footnotetext{
* Corresponding author: pcouto@lnec.pt
} 
although it does not reduce disparate phenomena to a common unitary (monetary) basis $[1,2]$. The multicriteria analysis was most recently used to gather the views of different partners and stakeholders in the evaluation of a regional development program co-financed by the three European Funds (the Structural Funds, the Cohesion Fund and the Instrument for Structural Policies for Pre-Accession).

The multicriteria analysis fits well with the management and evaluation of structural programs in partnership, as the views of national and supranational members can be expressed together, without losing any of their specificities, or without making too much concessions on their scales of value [2].

The present paper intends to frame the multicriteria analysis with the objective of optimizing investment projects in the rehabilitation of railway infrastructures. In this sense, its importance and potential will be evidenced for various stakeholders in the decisionmaking process. Moreover, will be presented the conceptual structure of a multicriteria analysis considering its constituent phases. Some preliminary remarks of the study under development will be presented.

\section{Multicriteria analysis: General considerations}

The main objective of a Multicriteria Analysis is to define and interconnect different analyzes considered in a decision-making process, if it is based on multiple choices and that the treatment given to each of the choices largely determines the final decision.

The multicriteria analysis can be used with the purpose of portraying the reasoning and subjective convictions of the different actors in the decision process on each question raised. It is often used in the synthesis of opinions expressed, to determine priorities, to analyze situations of conflict, to formulate recommendations or to provide operational guidance [3-5]. Its applications may include, for example [2]: i) make recommendations on the allocation of a specific budget or budget, whether the program is in progress or during the preparation of a subsequent program; ii) disseminate best practices, identifying areas of success and the most effective measures considered during a program to achieve success; iii) give feedback on project selection methods (choice of evaluation criteria, precise definition of evaluation criteria, weighting of different evaluation criteria); iv) improve the project selection process (ease of transferring criteria, rating scales and weighting degrees to the project selection system if the system is also organized based on a scoring / weighting scheme for multicriteria analysis).

The main strengths of a Multicriteria Analysis are the following: i) it allows to consider the individual values and opinions of several stakeholders and to process the functional relations within a complex network; ii) the involvement of an expert, the room for maneuver of policy-makers and similar voting methods, makes it an appropriate tool for approaching partnerships; iii) defines consensual areas (agreement on the classification of measures) and areas of divergence (reveals effective measures for some and ineffective for others).

The main limitations of a Multicriteria Analysis are: i) it is rarely used for situations other than those strictly equivalent to support for decision-making; ii) normally used to support the evaluation of projects before their execution; iii) specific implementation problems that may require the presence of an expert; iv) is not always used in an interactive way, as it should, and tends to set unstable criteria. 


\section{Multicriteria analysis structure}

The multicriteria analysis model to support the development of investment projects, which can be applied to investments in railway rehabilitation, is structured in different PHASES with a view to its implementation, as shown in Figure 1.

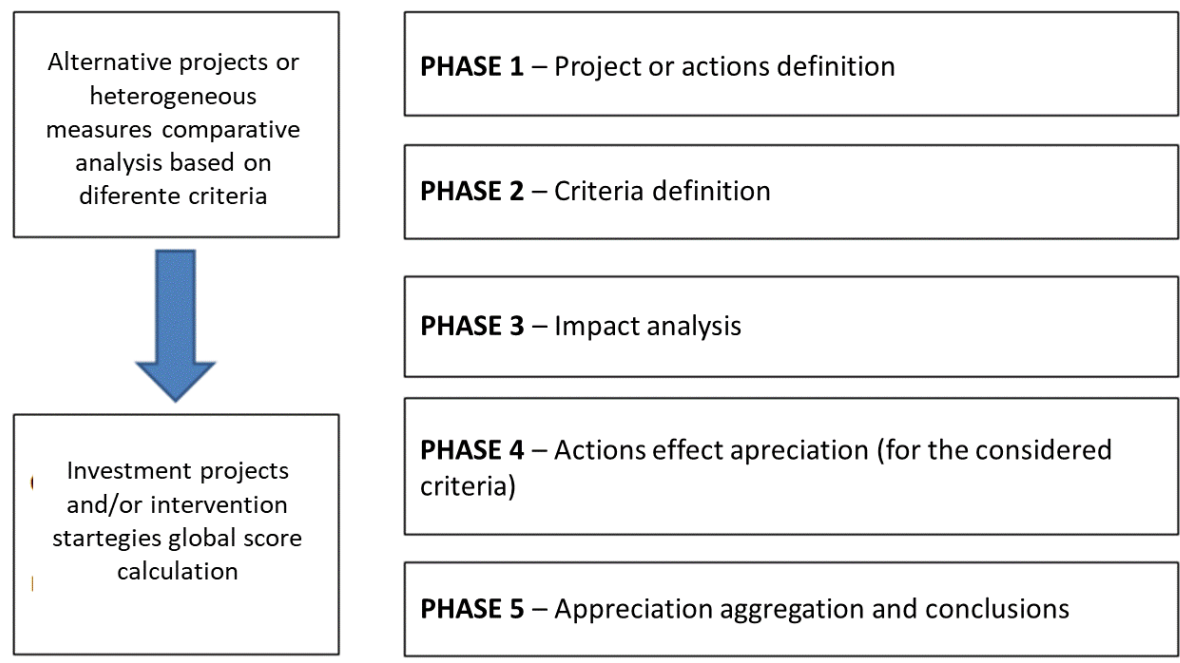

Figure 1. Multicriteria analysis structure

The effectiveness considered in the structuring of a Multicriteria Analysis will be accepted as solid and impartial provided that: i) the evaluation criteria have been validated by a previously selected follow-up group; ii) the conclusions on the impacts of each measure implemented and the impact classification matrix summarizing them have been validated (for example by the advisors to the project or by the monitoring group); iii) the weighting coefficients for the criteria have been established with the support of the advisors and with the support of the monitoring group.

\section{Multicriteria evaluation model applied to railway rehabilitation}

First, it is necessary to identify the objectives pursued by the decision-maker and his / her fundamental points of view, as well as the evaluation criteria, the set of performance descriptors associated with those criteria, and the options available [6].

Regarding to interventions in railway rehabilitation and the main problem of Selecting the most efficient rehabilitation technique, it should be borne in mind that [7] it is intended to: i) preserve the safety / integrity of its users / occupants; ii) maintaining operational structures; iii) minimize human and material losses; and iv) minimize intervention costs. In this sense it is possible to identify objectives related to technical points of view and economic points of view. In the first case, the following stand out: i) Objective 1 (O1): Minimization of structural and functional vulnerability; (ii) Objective 2 (O2): Ensure the functionality / operationality of the infrastructure; iii) Objective 3 (O3): Minimizing the complexity of the intervention; and (iv) Objective 4 (O4): Minimization of the intervention duration. Each defined objective can be associated with one or more criteria simultaneously. Objective 5 (O5) can still be considered later in the analysis: Minimization of the intervention cost, which is not a criterion, and its interest is essentially related to its 
use in an approach based on the principle of optimizing the benefit between different rehabilitation techniques.

For each of the objectives, quantitative and qualitative evaluation criteria can be identified simultaneously. Thus, associated with $\mathrm{O} 1$, it is possible to identify, for example, Criterion 1 (C1): Risk associated with each rehabilitation technique. For $\mathrm{O} 2$ it is possible to match, for example, Criterion 2 (C2): Resistance capacity. O3 corresponds, for example, to Criterion 3 (C3): Complexity of the intervention and Criterion 4 (C4): Degree of intrusion in the building. Finally, for $\mathrm{O} 4$ a Criterion 5 (C5): Time duration of the intervention execution. Criteria $1(\mathrm{C} 1), 2$ (C2), 4 (C4) and 5 (C5) can be defined on a qualitative scale with 5 levels of performance: 1) null / very low; 2) reduced; 3) moderate; 4) high; or 5) very high. Criterion 4 (C4) can be defined on a qualitative scale with 5 levels of performance: 1) zero; 2) little complex; 3) moderate; 4) complex; or 5) very complex [8].

Subsequently, and for the sake of operationalization of the evaluation process, a computer tool and / or software is used to verify the consistency of the assigned judgments, automatically, indicating the inconsistencies detected and suggesting changes in order to make all judgments consistent. Following the definition of all judgment matrices for each of the criteria, the software creates several functions of value (for quantitative criteria) and preference scales (for qualitative criteria).

The process of assigning weighting coefficients allows us to convert the scales of each of the criteria into global scores, considering all the criteria simultaneously, to make an evaluation according to the assumptions of the simple additive models [9].

\section{Final remarks}

In the present work the multicriteria analysis was presented, with emphasis on its constituent phases, in order to support the decision to intervene in the rehabilitation of railway infrastructures. The structuring of the problem reveals the most complex step given the number of specific and operational objectives defined.

In the application of the model in computer tool and / or specific software it is possible sometimes to feel some difficulty in distinguishing the difference of attractiveness among some of the levels of performance of the several criteria. Notice of inconsistencies in the adjudication phase of differences in attractiveness may reveal great utility in obtaining a coherent model and contributing to the reflector process by the decision maker.

The multicriteria methodology presented is applicable to the resolution of complex problems and may prove to be of great use to the decision-maker not only in decisionmaking but also in structuring and understanding the problem.

Presently are being developed some applications of the methodology presented in order to support railway infrastructures rehabilitation. The results obtained will be object of future analysis and publications.

\section{References}

[1] C. Bana e Costa, E. Beinat, Estruturação de modelos de análise multicritério de problemas de decisão pública. Centro de Estudos de Gestão - IST, Artigo de Investigação/Working Paper, n. ${ }^{\circ}$ 3/2010, ISSN 1646-2955 (2010)

[2] Guia para a Avaliação do Desenvolvimento Socioeconómico - EVALSED, MANUAL TÉCNICO II: Métodos e Técnicas Instrumentos de Enquadramento das Conclusões da Avaliação: Análise Multicritério. Comissão Europeia e Observatório QREN (2013).

[3] R. Clemen, T. Reilly, Making Hard Decisions with Decision Tools. Duxbury Thomson Learning, (2001). 
[4] Manual de análise de custos e benefícios dos projetos de investimento. Direção Geral de Política Regional da Comissão Europeia, (2003)

[5] Introduction to Cost-benefit analysis and alternative evaluation methodologies, Financial Management Reference Material n. ${ }^{\circ}$, Department of Finance and Administration, Australia, ISBN 1921182024 (2006).

[6] J. Oliver, D. Plotkin, J. Lesnik, D. Pirie, Condition and Performance Rating Procedures for Rubble Breakwaters and Jetties. U.S. Army Corps of Engineers (USACE), Champaign, IL, (1998)

[7] M.J. Falcão Silva, F. Salvado, M. Baião, Análise Custo-Benefício: Aplicação à reabilitação estrutural, Encontro Nacional Betão Estrutural (BE 2016), 2 a 4 de novembro, Coimbra, Portugal, Comunicação 80, (2016).

[8] M.J. Falcão Silva, F. Salvado, M. Baião, Aplicação de modelos de análise custobenefício a projetos de reabilitação de património construído, $2^{\circ}$ Encontro nacional sobre qualidade e inovação na construção (QIC 2016), 21 a 23 de novembro de 2016, LNEC, Lisboa, Portugal, Comunicação 53, 82016).

[9] C. Bana e Costa, J. Corte, J. Vansnick, 2012. MACBETH. International Journal of Information Technology \& Decision Making 11(2), 359-387, (2012) 